\title{
Transitioning to concept-based teaching: A discussion of strategies and the use of Bridges change model
}

\author{
William H. Deane * Marilyn Asselin \\ College of Nursing, University of Massachusetts-Dartmouth, North Dartmouth, Massachusetts, United States
}

Received: May 25, 2015

DOI: $10.5430 /$ jnep.v5n10p52
Accepted: June 25, 2015

Online Published: July 27, 2015

\begin{abstract}
Nursing education literature is replete with anecdotal accounts of continual struggle with curriculum content saturation. Recent calls, however, for transformation of nursing education have challenged nurse educators to explore innovative pedagogies and consider sweeping changes in the way future nurses are educated. In order to meet the needs of todays health care consumer, nursing education must move away from teacher-centered learning environments to one where students have the primary responsibility and play an active role in their learning. Concept-based teaching (CBT) pedagogies are a novel approach to educating students. Grounded in a constructivist learning theory, CBT allows faculty to build upon students' prior experiences and acquired knowledge from previous educational endeavors. Concepts that are applicable to multiple care settings are introduced by faculty early in the nursing program and are reinforced with exemplars. The change to CBT is a change in the pedagogical approaches with which faculty are unfamiliar. With student centered learning environments, minimal lecturing, and the increase use of collaborate teamwork, faculty must begin the transition to CBT. The Bridges change model includes three phases that can be used as a framework for identifying strategies to successfully transition to CBT. The use of reflective teaching practice strategies may also enhance the transition to CBT.
\end{abstract}

Key Words: Concept-based teaching, Nursing education, Bridges change model, Reflective teaching practice

\section{INTRODUCTION}

In the past decade, nurse scholars have recommended sweeping changes in the way the discipline prepares the future workforce for practice. ${ }^{[1,2]}$ There are multiple reasons for these proposed changes that include the complexity, setting, and care management challenges of today's patients, as well as an increase in the number of insured individuals accessing the health care system due to the implementation of the Affordable Care Act. Other recommendations to nursing education include the call for a seamless transition from education to practice, as well as a goal for $20 \%$ of the nursing workforce to have a Bachelors of Science in Nursing
(BSN) degree by 2020. ${ }^{[3]}$ Additionally, these recommendations challenge nursing programs to graduate nurses who have the ability to critically think and make care decisions using evidence-based practice in today's fast-paced health care environment.

To assist in meeting the care needs of today's health care consumer, many nursing programs have opted to integrate the Institute of Medicine's (IOM) quality and safety competencies within new and existing curriculums. ${ }^{[4]}$ Infusing the IOM competencies supports nursing programs in incorporating the knowledge, skills, and attitudes new graduates need to successfully implement quality and safety into their prac-

*Correspondence: William H. Deane; Email: wdeane@umassd.edu; Address: College of Nursing, University of Massachusetts-Dartmouth, North Dartmouth, Massachusetts, United States. 
tice environment. IOM recommendations also mirror what nursing education recognized in regard to content saturation throughout many nursing curriculums. Due to the perpetual growth of health care knowledge and advances in diagnoses and treatment options for diseases, nursing curriculums have reached a state of content overload. ${ }^{[5,6]}$

The IOM posits that newer educational models be developed that target concerns regarding content overload in many nursing programs. ${ }^{[1,3]}$ Recommendations from the IOM also describe the need for fundamental concepts to be taught that can be applied to multiple health care environments, and the need to move away from students practicing rote memorization of facts. ${ }^{[3]}$ Subsequently, nursing education has explored a variety of pedagogies to address these issues. One pedagogical approach, concept based teaching (CBT), has recently gained increased recognition. CBT can be defined as a student-centered learning environment that fosters the development of clinical reasoning skills using concepts and exemplars representative of patient care encounters. ${ }^{[7,8]}$ While literature exists on CBT, there is a dearth of information on transitioning to this model.

The purpose of this article is to discuss the necessity for pedagogical change, provide an overview of concept-based teaching, and key issues for faculty to consider when transitioning to concept-based teaching. Finally, Bridges' model of change ${ }^{[9]}$ will be used as a framework to discuss strategies to assist nurse educators who are transitioning from traditional pedagogies to CBT.

\section{BACKGROUND}

Despite the good intentions of nurse educators, students can no longer be taught the way that faculty were taught in our own nursing programs. ${ }^{[6,10]}$ Traditional pedagogical approaches in nursing education are no longer effective in preparing nurses to care for today's health care consumers in a variety of settings, as well as applying the knowledge, skills, and attitude to function as a competent clinician. ${ }^{[11,12]}$

Nursing education literature is replete with publications demonstrating the need for pedagogical changes to the approach in which nursing students are educated. ${ }^{[1,3,5,13]}$ Traditional pedagogy in nursing education has uniquely focused on a teacher-centered learning environment as compared to a learning setting that reflects a student-centered approach. A learner-centered environment can best be described as one that has a focus on learning with activities to engage the learner rather than solely imparting didactic information. Within a learner-centered environment, higher order thinking is fostered as students work in groups to solve clinically relevant health care scenarios. The role of the educator is a

Published by Sciedu Press facilitator of learning rather than a teacher. ${ }^{[10]}$

The $\mathrm{IOM}^{[3]}$ and the Robert Wood Johnson Foundation conducted a comprehensive review of the nursing profession that included an examination of the current nursing education system. The IOM calls for nursing education to re-evaluate, and update nursing curriculums to meet the changing needs of today's health care consumer, as well as improve on innovations in health sciences and technology. ${ }^{[3]}$ Another recommendation noted by the IOM is the need for nursing education to implement new models of delivery to meet the demands of the constant changes and improvements in disease management and patient care.

Furthermore, one recommendation is to introduce basic concepts that can apply to multiple health care settings, as compared to students memorizing facts to learn new material. In this approach, basic concepts such as oxygenation and perfusion are introduced early in the curriculum. Exemplars are used to demonstrate how the concept might be seen in different health care settings and disease processes in more advanced upper level nursing courses. Programs moving forward to implement concept-based curriculums further support these recommended changes in nursing education.

\section{Students as PASSive Learners in A TEACHER CENTERED CLASSROOM}

Many of today's nursing curriculums continue to follow a teacher-centered approach in educating future nurses. ${ }^{[6,14]}$ Students are educated in a passive learning environment in which they take notes, review slide presentations, and passively sit listening to lectures from nursing faculty that present content based on a medical model. The medical model approach used by nursing education primarily involves a class focused on a selected disease or condition, whereby the pathophysiology, etiology, diagnosis, treatment, nursing interventions, and outcomes are presented in a linear format from start to finish. ${ }^{[5,15]}$ Historically, This is the presentation format for all nursing content delivered in each nursing course throughout a traditional nursing curriculum. Moreover, courses continue to be devoted to specialties such as, medical/surgical, maternity, pediatrics, mental health, or community based nursing. Historically, nursing faculty teach a particular course based on their own individual specialty from nursing practice, thus allowing for the integration of personal experiences from clinical practice. This is also beneficial as it updates students on the changes in clinical practice that may have occurred after their textbook was published.

Nursing literature continues to be replete with experiences of how nurse educators teach in the classroom throughout the United States. There are multiple accounts of the so called 
sage on the stage, whereby, the nurse educator provides unidirectional lectures, incorporating the use of decks of slides displayed on a screen or white board, to a room of passively engaged students. Nurse educators who use this type of instructional pedagogy focuses on presenting a plethora of facts to students who feel that every pearl of wisdom they have should be passed along to the student. ${ }^{[16,17]}$

If nurse educators are not aware of what colleagues are covering in other courses, they may err on the side of caution and present material that might have been covered previously in the curriculum. Repetition of content by faculty may occur for fear that if the student doesn't hear it from them they may never hear it. While it seems this approach has been an effective educational practice in the past, there are drawbacks. Nurse educators and nursing education generally agree; many nursing courses are now content overloaded. ${ }^{[18]}$ This is evident by courses that have continually absorbed new content due to updated practice changes, while old, outdated content is not purged from the course. ${ }^{[5,19]}$

Content overload generates additional anxiety for nurse educators who feel pressured from large class sizes and increasing amounts of content to cover, all the while considering the best approach to fit all necessary content in the allotted semester time-frame. ${ }^{[10,20]}$

Oftentimes, nursing faculty are dismayed in trying learnercentered approaches in fear that all content will not be covered, or students who are accustomed to lecture delivery method, may voice concerns about not being able to learn any other way, or not having the time outside of the classroom for additional classroom prep work. ${ }^{[21]}$

With the call for recommended changes, many nursing programs have begun to implement curriculums that reflect the patient care needs of today's population and newer learner centered environments. Nursing programs have slowly transitioned from building their curriculum based on nursing grand theories and Tylerian focused behavioral objectives, to programs that are based on conceptual thinking.

\section{CONCEPT-BASED PEDAgOGY}

One of the pedogological changes in many nursing programs across the United States is the development and implementation of a concept-based pedagogy. Nursing is not the only discipline to embrace a conceptual teaching model for educating students. Changing to a concept-based curriculum is in line with multiple educational programs outside of nursing. ${ }^{\text {[22-25] }}$ These programs include those designed to teach English language learner students, ${ }^{[26]}$ primary school science, ${ }^{[27]}$ and conceptual learning in higher education. ${ }^{[25]}$ Social studies, mathematics, history, and science have all implemented con- ceptual teaching approaches beginning in elementary school and extending into high school programs. ${ }^{[27,28]}$

In the 1970s and 1980s, nursing was still attempting to prove itself as a complete and separate discipline within health care. During this time, many of the grand theories being developed were used as a designing framework for nursing curriculums. ${ }^{[12]}$ However, many nurse educators were unsure of how to teach conceptually. During this time faculty struggled to associate specific content to the concepts in the education of nursing students. ${ }^{[29]}$ With the advent of different types of curricular pedagogies, nursing has once again embraced the conceptual approach to teaching. Current curriculums are built on concepts that are most notable to nursing and are more easily understood by faculty and students. ${ }^{[8]}$

National Council Licensure Examination (NCLEX) pass rates are not the sole outcome of pre-licensure nursing program success, but are at the forefront of many nurse educators' minds when nursing programs begin discussing a change to a concept-based curriculum model. There is no current evidence that demonstrates a relationship between the incorporation of a concept-based curriculum to lower NCLEX pass rates. ${ }^{[8]}$ A low percentage of NCLEX candidate pass rates may indicate a need to review and revise the existing nursing curriculum or the program as a whole. Moreover, NCLEX pass rates generally decrease after any type of new curriculum is implemented or when the National Council of State Boards of Nursing increases the passing standard for NCLEX exams. ${ }^{[30,31]}$

\section{CONSTRUCTIVISM AND THE CONCEPT- BASED APPROACH TO TEACHING}

A concept-based approach to teaching is underpinned by Ausubels' learning theory that is derived from a constructivist paradigm. Ausubel describes the term "meaningful learning," as new knowledge that is connected to pre-existing knowledge in an active learning environment. ${ }^{[32]}$ New knowledge acquired by the learner is not lined up or stacked on top of previously acquired knowledge, but is integrated with previous knowledge and experience as a vessel to understand new, interlocking concepts. ${ }^{[32]}$ It is within the constructivist framework that the student begins to formulate the big picture and not solely undertake the task of memorizing non-interlinking facts.

Within a concept-based approach to teaching, concepts serve as the foundation for the curriculum. Concepts are defined as a mental construct that is timeless, universal, as well as abstract and broad. ${ }^{[33]}$ Concepts used within a concept-based approach to teaching are typically divided into categories 
that the professional nurse encounters in day-to-day practice. For example, biophysical concepts may include infection, fluid and electrolytes, mobility, and perfusion. Likewise, a second group relative to nursing includes psychosocial concepts consisting of communication, coping and stress, and health promotion. Also important are concepts that reflect nursing and professional practice such as health care quality, collaboration, information technology, and leadership. In a concept-based approach, the focus moves from content to concepts and conceptual learning. ${ }^{[5]}$ As students begin to understand basic nursing concepts, the use of exemplars, or examples, are introduced that relate to the main concept and are used to reinforce the primary concept. An example might be the concept of immunity presented in a class placed early in the curriculum and the use of an exemplar on the Human Immunodeficiency Virus (HIV) presented in a later course to help reinforce and provide an example of the main concept.

With CBT, once the students understand the primary concept and have gained further knowledge using exemplars, the new knowledge can be applied to a variety of health care environments and situations. ${ }^{[34,35]}$ For example, students who are taught conceptually are able to apply the exemplar of HIV to not only caring for the adult patient, but a newborn, expectant mother, as well as the adolescent. The important goal for nurse educators in a concept-based approach to teaching is that students make cognitive connections from theory to practice and not simply memorize facts. ${ }^{[8]}$

\section{BRIDGES TRANSITION MODEL OF CHANGE}

Bridges transition model ${ }^{[9]}$ is a novel approach to examine how individuals deal with and process change. Bridges describes change occurring through a transition of a threephase psychological process. In this process the individual progresses at his or her own pace as change occurs. Bridges delineates that there is a distinct but subtle difference between change and transition. Change, according to Bridges, is something that happens to individuals even though they may not like it. Transition is an internal psychological process that occurs in an individual's mind as they experience the change. During this process, the person internalizes and comes to terms with the details of the new situation the change brings about. ${ }^{[9]}$ Bridges divides the three phases of change into the letting go phase, the neutral zone, and finally, new beginnings. Within the three phases of the model, the individual experiences a letting go period where the individual comes to terms with their losses and begins to put their old identity behind them. Thereafter, individuals experience an in between time or neutral zone whereby the old is in the past, but the new is not fully functioning. This is also a critical period where the individual psychologically processes the re-alignment and re-patterning of the new. Finally, the individual transitions to a new identity and starts a new beginning with newfound excitement and energy, as well as a new sense of purpose that makes the change begin to work. Preparing for losses is a major struggle that individuals experience in the transition process. According to Bridges, the letting go of the old and acknowledging the loss is a process that a person in transition must experience for the change to be successful. It is also important to note, individuals experiencing the transition need encouragement and support from management or the governing body throughout this process. The situational aspect of instituting a change may occur quickly, but the psychological aspect associated with the change (the transition) occurs at a slower pace.

\section{Application OF BRIDges MOdel in TRANSITIONING TO CONCEPT-BASED TEACHING}

As nursing faculty undertakes the implementation of CBT there is need for both the actual change and the transition itself to be addressed. Bridges ${ }^{[9]}$ posits that dealing with losses and endings are equally important as the change itself. It is not only the change, implementing a new approach to teaching, but the psychological affects that occur within each individual effected by the change. During the letting go phase, it is important for nursing faculty to know what is ending and what is not, and who is letting go of what. Faculty affected by the change may be afraid of letting go of what made them successful in the past. For example, faculty members who have taught in pediatrics for many years and received superb student evaluation scores may have fears about letting go of their current way of teaching. Faculty may feel that with teaching conceptually, they may see student evaluation scores plummet, but also there is now a need to restructure how the class as a whole is organized and delivered. With the move from teacher centered to studentcentered classrooms, there is a need for faculty to devise new approaches to presenting concepts and exemplars. Faculty are encouraged to transcend away from asynchronous lectures and rote memorization of facts to an environment based on collaborative teams that fosters the skills needed to think like a nurse. A prime example might be the use of case studies that are reflective of the assigned concept or exemplar that pertains to a patient care scenario. Faculty who foster students working in groups, asking questions, and testing their assumptions demonstrates an inclusiveness of effective learning strategies within a concept-based curriculum. ${ }^{[8]}$ An important task during this phase of the change process is that faculty are provided educational resources on teaching 
conceptually.

It is critical that those involved in the change confront and elicit ways of dealing with anxiety in order for the change to be successful. If all those involved do not efficiently deal with this phase of change, the change process may be unsuccessful. Support from nursing administration and/or the parent institution as a whole for those effected by the implementation of a concept-based curriculum is critical. Support may include increased resources from administration in the form of physical and/or tangible material or peer facilitated group meetings to discuss and process the psychological aspects that are occurring during the change. Securing resources to assist faculty through the development and implementation of a new approach to teaching is crucial for success. Additional assistance and guidance may be obtained from faculty who have experience with CBT. For example, during budget development funds may be allocated that allow for expert consultation from an individual or group that has experience and knowledge in CBT approaches to guide faculty through the transition process. ${ }^{[8,36]}$ If travel budgets are minimal, there are other various telecommunication means in which faculty from nursing programs in different states or country can collaborate and provide support to one another. Likewise, deans and nursing directors can offer support by providing faculty with some variability in their work assignment or credit releases, particularly during the first year of the new curriculum implementation. Faculty oftentimes need to be reminded that it is an expectation of the educator role to remain current in educational pedagogies and the curriculum revision should not be viewed as a burden or extra work. ${ }^{[8]}$

\subsection{The neutral zone: Guiding faculty through the emo- tional wilderness}

Bridges defines the neutral zone as a time for psychological transition, and a critical period of realignment and repatterning. In this phase, communication among nursing faculty, as well as administration is pivotal. Faculty must be allowed the time to deal with anxieties brought about by the change to feel included and connected with both each other and the institution. This is the time where faculty may be thinking of leaving employment and begin to explore other teaching positions. Bridges ${ }^{[9]}$ notes that sick calls and time away from work may occur during the neutral zone as this is a period of high anxiety and low motivation amongst those involved Likewise, faculty members during this phase may return to the old ways of doing things. Bridges ${ }^{[9]}$ uses the term "polarization" to mean some members of the team want to move forward while others want to go back to their old ways of doing things. It is therefore important to ensure support during this time. The identification of faculty "champions" that have knowledge of CBT and are willing to listen, audit faculty classes, and offer peer faculty review comments may be helpful.

Nursing programs transitioning to a concept-based approach to teaching generally have a traditional cohort of students as well as students enrolled in the new redesigned curriculum. ${ }^{[37]}$ The traditional curriculum is the cohort of students remaining in the nursing program that are instructed under the old framework as this group of students may not be able to be switched to a conceptual model of learning half-way through their program of study. Teaching in both types of curriculums poses potential pedogological conflict in faculty that have a work assignment that requires them to teach in both the traditional and concept-based curriculum.

The neutral zone procedures, processes, and policies will continue to be refined. It is important that a process of orienting the students to the concept-based approach to teaching be established. This is an ideal opportunity for faculty to collaborate and develop the process and content of student orientation. Generally, incoming freshmen participate in a designated time before the semester begins for orientation. This provides faculty with an excellent time to orient students to materials that will be used in courses, as well throughout the curriculum. Student orientation should include an overview of how classes are structured in a conceptbased approach to teaching. Students need to understand that there may be minimal lecturing during class time, and an increase in the use of collaborative group work. Traditionally, there is more time spent getting students comfortable with conceptual learning in the first few classes offered in a concept-based curriculum. Faculty teaching in beginning courses must understand that they will need to devote time to help students begin to develop and use concept maps as a means of understanding interlinking connections between concepts.

Because this phase of the change process brings about a multitude of anxiety, changes in feelings, and periods of uneasiness, faculty should continually support one another. It is good practice to have faculty meet with one another or as a group and honestly discuss how they are dealing with the change brought about by changing to a new conceptbased curriculum. Reflective group dialog and facilitated peer support meetings may be helpful. These individual and group sessions are best used to share ideas of how faculty is structuring their class time and pedagogical approaches in delivering concepts and exemplars. ${ }^{[38]}$ This time can also be used to share thoughts, feelings, and emotions faculty are experiencing because of the change. Supporting one another in an open and honest way can possibly be the best tools to aid 
one another through the uneasy period as the new curriculum unrolls.

Another factor that may bring about an increase in anxiety and uneasiness at this time is student complaints. If students are accustomed to being taught in other classes through traditional teacher centered delivery methods, then they will most likely be uneasy about being taught in a student-centered environment with minimal to no lecturing. ${ }^{[21]}$ Students often voice complaints that they are paying to be taught and feel they cannot learn by many of the conceptual based approaches in the new curriculum. Therefore, conversations with deans and nursing directors should be more inclusive than directors and administrators inquiring as to how are things are going? Support for faculty during this time of in flux is critical to avoid a massive turnover within the program and help to foster self-confidence and a new sense of selfdirection. If faculty feels that administration is more focused on the curriculum than those who are implementing it, they may begin to feel undervalued and unappreciated.

\subsection{Moving forward: New beginnings}

Bridges $^{[9]}$ defines this phase in the change process as one in which people begin to foster new behaviors and make the change work. It is also a time where people adopt a new identity, experience, energy, and a new sense of purpose. When helping faculty through the transition process it is important to include the four P's: plan, purpose, picture, and part to play. If the purpose and plan were not clearly defined then it needs to be re-iterated at this point. The purpose of the curricular change should be brought back to the fundamental reasons why the old ways of educating students is no longer effective. The changes in the way health care is delivered, as well as producing nurses who can locate, analyze, interpret, and apply new information should be at the top of the list as to why the program transitioned to a concept-based curriculum.

Helping faculty envision how they will work together and complete their work is a valid means during this phase of the change process. This is also a period of helping faculty to understand the experience that is quite different from what they are used to. It is important for the nursing program to continue with group meetings that include faculty, deans, and directors to discuss the intricacies of how the change to a concept-based approach to teaching has shifted their way of thinking. Viable problems such as obstacles of how to present concepts or exemplars, as well as student issues, are all critical to faculty managing the change process in a supportive environment.

\section{INCORPORATING REFLECTIVE TEACHING PRACTICE INTO THE CHANGE PROCESS}

One of the first documented definitions of reflection was coined by Dewey ${ }^{[39]}$ as a form of stepping back from a situation that may be perplexing or precarious. Using reflective practice allows the individual to not act impulsively, therefore permitting for time to think and devise a plan of action Dewey. ${ }^{[39]}$

Reflective practice can be thought of as a form of selfassessment that also fosters professional development and growth. ${ }^{[40]}$ Through reflection, one looks back on an experience and thinks about its meaning in relationship to oneself. Throughout the change process, reflective teaching practice (RTP) is an approach that can be useful to faculty transitioning to concept-based pedagogy. RTP can be defined as a process whereby one looks back on teaching that has occurred, and reflects on the experience itself. ${ }^{[41]}$ It can be viewed as a form of self-evaluation, whereby faculty consider what went right, what went wrong, and what can be changed. RTP is deeper than the change itself, and includes the psychological aspects of the transition process and how it affects the person's thoughts, feelings, and emotions. Reflective questions that educators might ask themselves during the change process may include the following: How am I dealing with the change internally? How can I make this journey better for my peers, my students, and myself? What is the feedback from my students in regards to my conceptual teaching style? Am I achieving the outcomes that I wanted? What have I learned? What would I do differently in the future? When faculty engages in reflective practice it helps them to understand how changes in their thinking are integrated into the classroom. Engaging in one-to-one mentoring and journaling are just two forms of how RTP can be accomplished.

\section{Conclusion}

As faculty begin the move to CBT and undertake the implementation of new pedagogical approaches to educating nursing students, the transition process continues. During the implementation of a new concept-based approach to teaching there should continue to be not only support for the faculty, but also education on the process of teaching conceptually. Transition to a CBT approach may be aided by education in the form of expert guests, collaborating with those who have already implemented a concept-based curriculum, or selfdirected learning. Using the Bridges model of change can be an ideal framework to guide those involved in undertaking the task of re-writing and implementing a new curriculum. Because of the paucity of research completed by nursing 
education on the use of CBT, there is a need for studies to be completed on its effectiveness as a pedagogical approach in educating nurses. There is also a need for additional research studies to address both the experience of students and faculty who are part of a concept-based curriculum.

\section{CONFlicts OF InTEREST Disclosure}

The authors declare that there is no conflict of interest.

\section{REFERENCES}

[1] Benner P, Sutphen M, Leonard V, et al. Educating nurses: A call for radical transformation. San Fransisco, CA: Jossey-Bass; 2010.

[2] National League for Nursing. Position statement: Transforming nursing education. 2005. Available from: http://www.nln.org/abou tnln/positionstatements/transforming052005.pdf

[3] Institute of Medicine. The future of nursing: Leading change, advancing health. 2010. Available from: http://www . iom. edu/Re ports/2010/The-Future-of-Nursing-Leading-Change-A dvancing-Health/Report-Brief-Education . aspx?page $=2$

[4] QSEN Institute. Pre-licensure KSAS. 2012. Available from: http: //qsen.org/competencies/pre-licensure-ksas/

[5] Giddens J, Brady D. Rescuing nursing education from content saturation: The case for a concept-based curriculum. Journal of Nursing Education. 2007; 46(2): 65-69. Available from: http: //www.healio.com/nursing/journals/jne PMid:17315564

[6] Stanley MJC, Dougherty JP. A paradigm shift in nursing education: A new model. Nursing Education Perspectives. 2010; 31(6): 378-380. PMid:21280445

[7] Erickson HL, Lanning LA. Transitioning to concept-based curriculum and instruction. Thousand Oaks, CA: Corwin Press Inc; 2014.

[8] Giddens J, Caputi L, Rodgers BL. Mastering concept-based teaching: A guide for nurse educators. St. Louis, MI: Elsevier; 2015.

[9] Bridges W. Managing transitions: Making the most of change (2nd ed.). New York, NY: Perseus Publishing; 2013.

[10] Dalley K, Candela L, Benzel-Lindley J. Learning to let go: The challenge of de-crowding the curriculum. Nurse Education Today. 2008; 28(1): 62-69. PMid:17397973 http://dx.doi.org/10.1016/j .nedt.2007.02.006

[11] DiCarlo SE. Too much content, not enough thinking, and too little fun! Advances in Physiology Education. 2009; 33(4): $257-$ 264. PMid:19948670 http://dx.doi.org/10.1152/advan. 000 75.2009

[12] Hardin PK, Richardson SJ. Teaching the concept curricula: Theory and method. Journal of Nursing Education. 2012; 51(3): 155-159. PMid:22283151 http://dx.doi.org/10.3928/01484834-201 20127-01

[13] Rentschler DD, Spegman AM. Curriculum revolution: Realities of change. Journal of Nursing Education. 1996; 35(9): 389-393. Available from: http://www.healio.com/nursing/journals/jne PMid:8950712

[14] Getha-Eby TJ, Beery T, Xu Y, et al. Meaningful learning: Theoretical support for concept-based teaching. Journal of Nursing Education. 2014; 53(9): 494-500. PMid:25138570 http://dx.doi.org/10 3928/01484834-20140820-04

[15] Bristol TJ, Rosati LJ. Successful concept-based learning through the integration of technology. Teaching and Learning in Nursing. 2013; 8(3): 112-116. http://dx.doi.org/10.1016/j.teln.2013.0 4.001

[16] Brandon AF, All AC. Constructivism theory analysis and application to curricula. Nursing Education Perspectives. 2010; 31(2): 89-92. PMid:20455364
[17] Quinn-Griffin M, Novotny J. Planning to give a lecture A nuts and bolts approach to teaching nursing (4th ed., pp. 61-71). New York, NY: Springer Publishing Company; 2012.

[18] Forbes MO, Hickey MT. Curriculum reform in baccalaureate nursing education: Review of the literature. International Journal of Nursing Education Scholarship. 2009; 6(1): 16. PMid:19725808 http://dx.doi.org/10.2202/1548-923X.1797

[19] Ironside PM. "Covering content" and teaching thinking: Deconstructing the additive curriculum. Journal of Nursing Education. 2004; 43(1): 5-12. Available from: http://www.healio.com/nursing /journals/jne PMid:14748529

[20] Lewis LS. Outcomes of a concept-based curriculum. Teaching and Learning in Nursing. 2014; 9(2): 75-79. http://dx.doi.org/10. 1016/j.teln.2013.12.002

[21] Greer AG, Pokorny M, Clay MC, et al. Learner-centered characteristics of nurse educators. International Journal of Nursing Education Scholarship. 2010; 7(1): 15. PMid:20196765 http://dx.doi.org /10.2202/1548-923X.1710

[22] Chappell KK, Killpatrick K. Effects of concept-based instruction on students' conceptual understanding and procedural knowledge of calculus. PRIMUS. 2003; 13(1): 17-37. Available from: http:// dl.acm.org/citation.cfm?id=782668 http://dx.doi.org /10.1080/10511970308984043

[23] Chirichello M, Eckel J, Pagliaro G. Using concepts and connections to reach students with integrated curriculum. Middle School Journal. 2005; 36(5): 37-42. Available from: http://www . amle.org/ServicesEvents/MiddleSchoolJour nal/tabid/175/Default.aspx

[24] McCoy JD, Ketterlin-Geller LR. Rethinking instructional delivery for diverse student populations: Serving all learners with concept-based instruction. Intervention in School and Clinic. 2004; 40(2): 88-95. http://dx.doi.org/10.1177/10534512040400020401

[25] Mackenzie J. Conceptual learning in higher education: Some philosophical points. Oxford Review of Education. 2008; 34(1): 75-87. http://dx.doi.org/10.1080/03054980701565006

[26] Al-Qatawneh SK, Allen A, Sefton T, et al. The effect of conceptbased curriculum and instruction in motivating learners of English as a foreign language. Journal of Teaching and Learning. 2013; 9(1): 101.

[27] Georghiades P. Beyond conceptual change learning in science education: Focusing on transfer, durability and metacognition. Educational Research. 2000; 42(2): 119-139. http://dx.doi.org/10.1080 1001318800363773

[28] Ganem-Gutierrez GA, Harun H. Verbalisation as a mediational tool for understanding tense-aspect marking in English: An application of concept-based instruction. Language Awareness. 2011; 20(2): 99119. http://dx.doi.org/10.1080/09658416.2010.551125

[29] Giddens JF, Wright M, Gray I. Selecting concepts for a conceptbased curriculum: Application of a benchmark approach. Journal of Nursing Education. 2012; 51(9): 511-515. PMid:22849765 http://dx.doi.org/10.3928/01484834-20120730-02 
[30] Giddens J, Morton N. Report card: An evaluation of a concept-based curriculum. Nursing Education Perspectives. 2010; 31(6): 372-377. PMid:21280444

[31] National Council of State Boards of Nursing. Passing standard/FAQ. 2013; Available from: https://www.ncsbn.org/4699.htm

[32] Ausubel DP, Novak JD, Hanesian H. Educational psychology: A cognitive view (2nd ed.). Chicago, IL: Hold, Rinehard, and Winston; 1978.

[33] Erickson HL. Concept-based curriculum and instruction: Teaching beyong the facts. Thousand Oaks, CA: Corwin Press, Inc; 2002.

[34] Giddens J, Brady D, Brown P, et al. A new curriculum for a new era of nursing education. Nursing Education Perspectives. 2008; 29(4): 200-204. Available from: http://www.nln.org/nlnjournal/i ndex.htm PMid:18770947

[35] Goodman T. Nursing education moves to a concept-based curriculum. AORN. 2014; 99(6): C7-8. http://dx.doi.org/10.1016/S00 01-2092 (14) 00534-1

[36] Brady D, Welborn-Brown P, Smith D, et al. Staying afloat: Surviving curriculum change. Nurse Educator. 2008; 33(5):
198-201. Available from: http://journals.1ww.com/nur seeducatoronline/pages/default.aspx $\quad$ PMid:18769319 http://dx.doi.org/10.1097/01.NNE.0000334776.05643.30

[37] Iwasiw CL, Goldengerg D, Andrusyszyn M. Planning curriculum implementation Curriculum development in nursing education (2nd ed.). Sudbury, MA: Jones and Bartlett Publishers; 2009.

[38] Schaefer KM, Zygmont D. Analyzing the teaching style of nursing faculty: Does it promote a student-centered or teacher-centered learning environment? Nursing Education Perspectives. 2003; 24(5): 238-245. Available from: http://www.nln.org/nlnjournal/i ndex.htm PMid:14535144

[39] Dewey J. How we think: A restatement of the relation of reflective thinking to the educative process. Chicago, IL: DC Health and Co; 1933.

[40] Schon DA. Educating the reflective practitioner. San Francisco, CA: Jossey-Bass Inc. Publishers; 1987.

[41] Hayward LM. Becoming a self-reflective teacher: A meaningful research process. Journal of Physical Therapy Education. 2010; 14(1): 21. Available from: http://www.aptaeducation.org/member s/jopte/ 